\title{
An Economic Evaluation of Voretigene Neparvovec for the Treatment of Biallelic RPE65-Mediated Inherited Retinal Dystrophies in the UK
}

\author{
Daniel Viriato $\cdot$ Natalie Bennett - Raisa Sidhu $\cdot$ Elizabeth Hancock \\ Hannah Lomax · David Trueman · Robert E. MacLaren
}

Received: December 12, 2019 / Published online: February 7, 2020

(C) The Author(s) 2020

\begin{abstract}
Introduction: Voretigene neparvovec ( $\mathrm{VN})$ is a gene therapy and the first approved pharmacological treatment for biallelic RPE65-mediated inherited retinal dystrophies (IRD), a rare condition that starts in early life and causes vision to progressively deteriorate towards complete blindness. In a phase III trial, treatment with VN significantly improved functional vision and visual function, and in October 2019 the National Institute for Health and Care Excellence (NICE) Highly Specialised Technologies
\end{abstract}

Enhanced Digital Features To view enhanced digital features for this article go to https://doi.org/10.6084/ m9.figshare.11637108.

Electronic supplementary material The online version of this article (https://doi.org/10.1007/s12325020-01243-y) contains supplementary material, which is available to authorized users.

D. Viriato

Novartis Pharma AG, Basel, Switzerland

N. Bennett · R. Sidhu

Novartis Pharmaceuticals UK Limited, London, UK

E. Hancock $(\bowtie) \cdot H$. Lomax · D. Trueman

Source Health Economics, London, UK

e-mail: ehancock@source-he.com

R. E. MacLaren

Oxford Eye Hospital, Oxford University Hospitals

NHS Foundation Trust and NIHR Oxford Biomedical

Research Centre, Oxford, UK
(HST) process recommended VN for patients in England and Wales. We assessed the cost-effectiveness of $\mathrm{VN}$ compared with best supportive care (BSC) in individuals with biallelic RPE65mediated IRD in the UK.

Methods: A Markov model was developed to estimate the incremental cost per quality-adjusted life-year (QALY) gained for VN compared with BSC, from the perspective of the UK National Health Service and Personal Social Services. Phase III trial data were used to inform transition probabilities up to year 1, after which the treatment effect was assumed to be maintained for 40 years, followed by a decline in vision. A bespoke elicitation exercise involving clinical experts, patients and carers was conducted to estimate utility values for each model health state.

Results: At list price, $\mathrm{VN}$ is associated with incremental costs of $£ 612,404$ and incremental QALYs of 6.4, resulting in an incremental costeffectiveness ratio (ICER) of $£ 95,072$ per QALY gained. Voretigene neparvovec is associated with a significant undiscounted QALY gain (20.5) and is therefore eligible for additional QALY weighting under the NICE HST process; an ICER of up to $£ 205,000$ per QALY gained could be considered cost-effective under this framework.

Conclusion: The results of the model show VN to be a cost-effective use of healthcare resources in the UK at list price. The availability of a commercial discount in the UK (as considered in the NICE appraisal) means that in reality the ICER will be even lower. 
Plain Language Summary: Plain language summary available for this article.

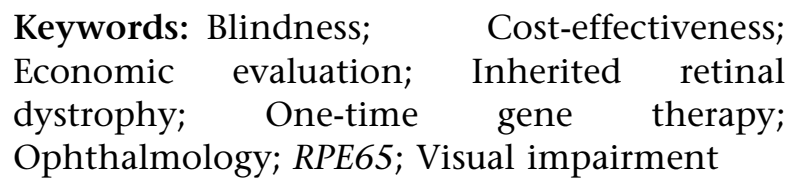

\section{Key Summary Points}

Why carry out this study?

Voretigene neparvovec ( $\mathrm{VN})$ is a gene therapy treatment for biallelic RPE65mediated inherited retinal dystrophies, an extremely rare and previously untreatable condition that leads to complete blindness in almost all patients. The condition has a profound impact on patients' quality of life, and visual impairment is associated with economic burden at the individual and societal levels.

The aim of the study was to determine if VN can be considered a cost-effective use of National Health Service (NHS) resources in the UK, by modelling the costs incurred and benefits gained from treatment, compared with the current standard of care.

\section{What was learned from the study?}

The cost-effectiveness model determined the incremental cost-effectiveness ratio (a measure of cost per unit benefit gained) to be $£ 95,072$ per quality-adjusted life-year gained.

This is lower than typical thresholds below which technologies for rare diseases are generally considered to be cost-effective in the UK, and so VN is expected to be a costeffective use of NHS resources.

\section{PLAIN LANGUAGE SUMMARY}

Biallelic RPE65-mediated inherited retinal dystrophies (IRD) are rare genetic disorders affecting the retina (the light-sensitive membrane at the back of the eye). Patients often experience the first symptoms of not being able to see in the dark from birth, with vision worsening in childhood and eventually leading towards complete blindness. Voretigene neparvovec $(\mathrm{VN})$ is a gene therapy medicine and the first drug treatment for biallelic RPE65-mediated IRD. It works by delivering a healthy copy of the faulty RPE65 gene into the retina. In several clinical trials, patients experienced significant improvements in their vision following treatment with $\mathrm{VN}$, and side effects were generally mild.

In some countries, once a new treatment is shown to be safe and effective, it is automatically available to patients. However, in the UK, consideration is also given to the value for money the treatment represents. With limited healthcare budgets, it is important that the benefits come at a reasonable cost. Value for money can be calculated by performing costeffectiveness analyses; these are used by the National Institute for Health and Care Excellence (NICE) in the UK to decide whether new treatments should be made available on the National Health Service (NHS). In this article we present the results of a cost-effectiveness analysis of VN for the treatment of biallelic RPE65mediated IRD.

An economic model was built to calculate the net clinical benefit of $\mathrm{VN}$ (using results from the clinical trial) and the net costs compared with current clinical practice. The ratio of the two provides a measure of the cost of the treatment per unit of health gained. Model results show that for $\mathrm{VN}$ this ratio falls below the threshold specified by NICE, demonstrating that VN is likely to be a cost-effective use of NHS resources.

\section{INTRODUCTION}

\section{Disease Background}

Inherited retinal dystrophies (IRD) are a heterogenous group of rare genetic diseases characterised by progressive vision loss, leading to complete blindness in almost all patients 
$[1,2]$. They can be caused by mutations in $>260$ genes, including the RPE65 gene. Biallelic RPE65-mediated IRD is very rare, with an estimated prevalence of 180 people in England [3].

Visual impairment in individuals with biallelic RPE65-mediated IRD can present at a range of ages, from infancy to adolescence. The first symptom is typically nyctalopia (night blindness), which causes difficulty seeing in dim light, such as at dusk or at night. This is followed by progressive visual field (VF) loss, and eventually peripheral blind spots merge to produce tunnel vision. Loss of central vision in the advanced stages of the disease leads to complete blindness [4-6].

The effects of the inexorable progression towards complete blindness are life-changing and lifelong [2]. Children affected by visual impairment are more likely to experience social and economic disadvantage [7], and the impacts of reduced mobility and independence become an increasing problem as young adults progress into further and higher education. Severe visual impairment is associated with an increased risk of depression, anxiety and sleep disorders [8-13], and studies have also reported an increased risk of depression among caregivers of those with visual impairment [14, 15]. It is estimated that the full lifetime cost of blindness in individuals with biallelic RPE65-mediated IRD in the UK is between $£ 1.6$ and $£ 1.8$ million. Approximately $70 \%$ of lifetime costs are associated with lost productivity, with $20 \%$ of costs incurred by the healthcare system [16].

\section{Voretigene Neparvovec}

Voretigene neparvovec ( $\mathrm{VN}$ ) is an adeno-associated virus vector-based gene augmentation therapy approved by both the US Food and Drug Administration and the European Medicines Agency for the treatment of patients with confirmed biallelic RPE65-mediated IRD and sufficient viable retinal cells $[17,18]$. It is administered once per eye, with the aim of restoring the visual cycle and arresting or reversing the decline in visual function.

Prior to the approval of VN, no pharmacological treatments were available for patients with biallelic RPE65-mediated IRD, with support limited to measures allowing the management of the disease such as low-vision aids. Retinal prostheses are available in some countries (for adults aged $\geq 25$ with severe visual impairment), but not the UK (where they are recommended for research purposes only). However, these do not alter the disease process and the inevitable decline in retinal function.

\section{Clinical Trials}

In a phase III trial, patients experienced significant improvements in visual function (the performance of the eyes) and functional vision (the ability to perform activities of daily living that are dependent on vision) following treatment with VN [2]. Following treatment, significant improvements were observed in the ability of patients to navigate independently in low-tomoderate light conditions, in light sensitivity and in VF, and a numerical improvement was observed in mean visual acuity (VA). These improvements manifested rapidly (within the first 30 days after subretinal delivery) and were maintained through to the most recent published follow-up time points (year 4 [19]).

In earlier phase I trials, improvements in vision following treatment were maintained through to the latest published follow-up time points (7.5 and 4 years), providing supporting evidence on the durability of the treatment effect $[20,21]$.

\section{Cost-Effectiveness Analysis}

To make decisions about the best use of finite budgets, healthcare decision makers often rely on cost-effectiveness analyses. The primary outcome of cost-effectiveness analyses is the incremental cost-effectiveness ratio (ICER), calculated as the incremental costs associated with a new treatment divided by the incremental benefits. The latter can be expressed using quality-adjusted life years (QALYs; a product of quality and quantity of life) [22].

Some decision-making bodies have specific cost-effectiveness thresholds, below which treatments are usually considered cost-effective. 
Voretigene neparvovec meets the criteria for the National Institute for Health and Care Excellence's (NICE's) Highly Specialised Technologies (HST) process, used for evaluating therapies for very rare conditions, which has a baseline cost-effectiveness threshold of $£ 100,000$ per QALY gained. However, for treatments that offer a substantial increase to quality/quantity of life ( $>10$ undiscounted QALYs), additional QALY weighting applies so that the threshold can effectively be between $£ 100,000$ and $£ 300,000$ depending on the extent of the benefit [23]. Voretigene neparvovec has been recommended by NICE for commissioning in England and Wales [3].

\section{Objective}

The objective of this analysis is to present an estimate of the cost-effectiveness of VN at list price compared with best supportive care (BSC) for the treatment of individuals with biallelic RPE65-mediated IRD in the UK.

\section{METHODS}

\section{Decision Problem}

A cost-effectiveness analysis was conducted comparing VN with BSC in individuals with biallelic RPE65-mediated IRD who have sufficient viable retinal cells. The lack of treatment options prior to the development of $\mathrm{VN}$ means that BSC is limited to measures supporting the management of the disease, such as low-vision aids and genetic counselling.

The primary outcome of interest was the ICER expressed as the cost per QALY gained. Costs were considered from the perspective of the National Health Service (NHS) and Personal Social Services in England and Wales, with costs falling outside of the healthcare system included in scenario analyses; the perspective on outcomes included direct health effects for both patients and carers. A lifetime time horizon was considered, and costs and outcomes were discounted at an annual rate of $3.5 \%$ in line with current NICE guidance [24]. A scenario is considered assuming discount rates of $1.5 \%$, in line with NICE guidance on treatments with substantial long-term treatment effects [24].

This article does not contain any new studies with human or animal subjects performed by any of the authors. The economic model uses data from a published phase III trial [2].

\section{Model Structure}

A Markov state transition model was constructed, with five alive health states determined based on the worst of VA and VF (i.e., whichever of VA or VF would assign the patient to a more severe health state) and death (Fig. 1); health state cut points were derived using American Medical Association guidelines (see supplementary materials for further details). The average VA and VF across both eyes were assumed, with a scenario considering health states defined based on VA and VF in the bestseeing eye.

Health states could not be defined based on the multi-luminance mobility test (MLMT) (the primary outcome of Study 301) because no data are available linking this outcome to costs, utilities or mortality, and no data are available on the long-term change in this outcome. However, the MLMT is a functional endpoint that captures clinical changes in each of VA, VF and full-field light sensitivity threshold (FST; a measure of light sensitivity), and so health states defined by a combination of VA and VF are expected to capture some changes in MLMT associated with $\mathrm{VN}$; the inability to capture changes in light sensitivity is expected to result in conservative estimates of cost-effectiveness for $\mathrm{VN}$.

A cycle length of 1 year was used, and halfcycle correction was implemented.

The model consists of an initial phase and a long-term phase. In the initial phase, data from Study 301 were used to inform the transition probabilities between baseline and year 1 in each of the BSC and VN arms; in this phase, it was assumed that individuals may move to either better or worse health states. In the longterm phase, the year 1 distribution of $\mathrm{VN}$ patients was assumed to be maintained for 


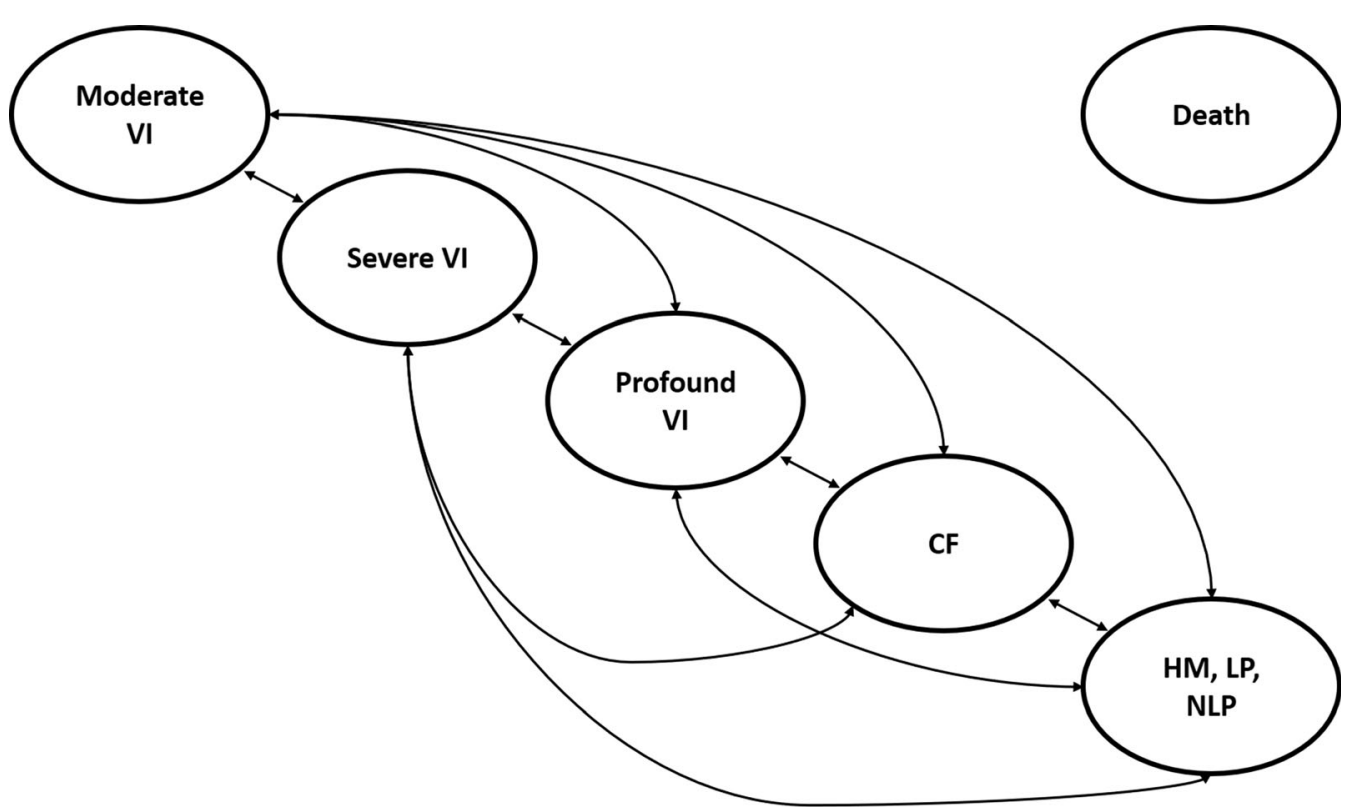

Fig. 1 Model schematic. $C F$ counting fingers, $H M$ hand motion, $N L P$ no light perception, $V I$ visual impairment

40 years, after which natural history data in individuals with biallelic RPE65-mediated IRD were used to model the long-term decline in visual function in this population. A 40-year duration of treatment effect was assumed to represent a reasonable midpoint between the absolute minimum ( 7.5 years of follow-up with no loss of efficacy [20]) and potential maximum based on preclinical data and clinical expert opinion (lifetime treatment effect of approximately 70 years). Patients receiving BSC were assumed to progress as per the natural history data immediately following year 1 . In the longterm phase, it was assumed that individuals may only progress to a worse state. Patients were exposed to the risk of mortality from all health states.

\section{Clinical Data}

The baseline health state distribution and transition probability matrices for the first year of the model were derived from Study 301 (Tables 1, 2, 3; see supplementary materials for further details). Scenarios are considered in which the baseline health state distribution is taken from the natural history study, and data from delayed intervention patients in the extension phase of Study 301 are included when calculating first-year transition probability matrices. The baseline age in the model is 15 years, reflecting the average age of patients enrolled in Study 301. Following the treatment of existing patients who are eligible for treatment with $\mathrm{VN}$, treatment of incident patients may be expected to occur at a younger age; however, subgroup analyses based on age were not considered feasible given the low number of patients enrolled in Study 301.

Patient-level data from a retrospective chart review study designed to describe the

Table 1 Baseline health state distribution

\begin{tabular}{ll}
\hline Health state & Proportion at baseline (\%) \\
\hline HS1: moderate VI & 23 \\
HS2: severe VI & 32 \\
HS3: profound VI & 23 \\
HS4: CF & 19 \\
HS5: HM, LP, NLP & 3 \\
\hline
\end{tabular}

$C F$ counting fingers, $H M$ hand motion, $H S$ health state, $L P$ light perception, $N L P$ no light perception, $V I$ visual impairment 
Table 2 Transition probability matrix for initial phaseBSC arm

\begin{tabular}{lccccc}
\hline \multicolumn{7}{l}{ Health state at 1 year } \\
\cline { 2 - 7 } & $\begin{array}{l}\text { HS1 } \\
(\%)\end{array}$ & $\begin{array}{l}\text { HS2 } \\
(\%)\end{array}$ & $\begin{array}{l}\text { HS3 } \\
(\%)\end{array}$ & \multicolumn{1}{l}{$\begin{array}{l}\text { HS4 } \\
(\%)\end{array}$} & $\begin{array}{l}\text { HS5 } \\
(\%)\end{array}$ \\
\hline \multicolumn{7}{l}{ Health state at baseline } \\
HS1 & 100 & 0 & 0 & 0 & 0 \\
HS2 & 25 & 50 & 0 & 25 & 0 \\
HS3 & 0 & 0 & 100 & 0 & 0 \\
HS4 & 0 & 0 & 100 & 0 & 0 \\
HS5 & 0 & 0 & 0 & 100 & 0 \\
\hline
\end{tabular}

Key: HS1, moderate visual impairment; HS2, severe visual impairment; HS3, profound visual impairment; HS4, counting fingers; HS5, hand motion, light perception to no light perception

Table 3 Transition probability matrix for initial phase$\mathrm{VN}$ arm

\begin{tabular}{lllll}
\multicolumn{4}{l}{ Health } & state at 1 year \\
\hline $\begin{array}{l}\text { HS1 } \\
(\%)\end{array}$ & HS2 & HS3 & HS4 & HS5 \\
$(\%)$ & $(\%)$ & $(\%)$ & $(\%)$ \\
\hline
\end{tabular}

Health state at baseline

\begin{tabular}{rrrrrr} 
HS1 & 100 & 0 & 0 & 0 & 0 \\
HS2 & 83 & 17 & 0 & 0 & 0 \\
HS3 & 50 & 50 & 0 & 0 & 0 \\
HS4 & 50 & 0 & 25 & 25 & 0 \\
HS5 & 0 & 50 & 0 & 25 & 25 \\
\hline
\end{tabular}

Key: HS1, moderate visual impairment; HS2, severe visual impairment; HS3, profound visual impairment; HS4, counting fingers; HS5, hand motion, light perception to no light perception

natural history of biallelic RPE65-mediated IRD (RPE65 NHx) informed the long-term natural history of the disease under standard of care [25]. All patients with confirmed RPE65 mutations, from seven international centres, were enrolled in this study and their charts were collected, following redaction of protected health information. Longitudinal ocular history and visual function testing data were abstracted from the collected charts and analysed.
A multistate survival model using data from the natural history study was developed using methods detailed by Crowther and Lambert [26] to inform the transitions between the five 'alive' health states. Six parametric distributions were tested: exponential, generalised gamma, Gompertz, log-logistic, log-normal and Weibull. These models were compared using the Akaike and Bayesian information criterion (AIC and BIC, respectively) and analysis of the Cox Snell residuals. The Weibull model was selected on the basis of AIC and BIC; further details are available in the supplementary materials.

Modelled adverse events included all those considered to be related to either the treatment or the administration procedure in the $\mathrm{VN}$ arm of Study 301, occurring in greater than one patient, and expected to be associated with an impact on quality of life and/or cost [2]. Adverse events meeting these criteria were cataract, eye inflammation and increased intraocular pressure (IOP).

Background mortality was modelled using general population life tables for England and Wales [27]. This approach is expected to be conservative, given that visual limitations have been shown to be associated with an increased risk of death [28].

\section{Utility Data}

A systematic literature review was conducted to identify utility values in individuals with biallelic RPE65-mediated IRD; however, no utility data were identified in this population. Given the ultra-rare nature of the condition, it was not considered feasible to recruit a representative sample of patients such that utility data could be collected prospectively. A bespoke utility study was therefore conducted to estimate utility values associated with each of the model health states [29], wherein bespoke vignettes were developed and assessed by clinicians in terms of their impact on standard generic health-related quality of life instruments (EQ5D-5L and HUI3). This approach has been taken previously in rare conditions [30, 31].

Health state descriptions (vignettes) were developed through a process that combined 
information gathered from five patient/caregiver testimonials, expert advisory board feedback from 12 general specialists from leading ophthalmology centres in the US and interviews with six rehabilitation experts and three caregivers. The resulting five vignettes described different levels of visual function in biallelic RPE65-mediated IRD, corresponding to each of the health states in the model.

Six retina specialists, all with experience in IRD, completed each of the EQ-5D-5L and the HUI3 for the five vignettes. The EQ-5D-5L was scored using the van Hout et al. algorithm [32], and the HUI3 was scored in line with developer instructions. The resulting utility values are presented in Table 4; full details of the methods and results of the bespoke utility study have been published previously [29].

The EQ-5D-5L scores ranged between 0.71 and 0.15; the HUI3 scores for each health state were found to be lower than the corresponding EQ-5D-5L score, with a range from 0.52 to -0.04. Despite the relatively small sample size of six clinicians, the standard deviation around the utility estimates are relatively low, indicating a high level of agreement between the clinical experts.

Utility values derived from the EQ-5D-5L were selected for the model base case on the basis that the EQ-5D is the preferred measure of health-related quality of life for UK health technology assessment bodies [24, 33]. However, the HUI3 contains a vision component and so may be expected to better capture changes in quality of life corresponding to changes in vision. A scenario was therefore considered using utility values based on the HUI3.

The utility decrements and durations of event for cataracts and eye inflammation were sourced from NICE guidelines on age-related macular degeneration [34]. In the absence of other data, the utility decrement for increased IOP was conservatively assumed to be the same as that for uncontrolled/severe glaucoma [35]. The duration of increased IOP was assumed to be 1 month, given that all increased IOP events observed in Study 301 were fully resolved within 1 month [2].

The disutility associated with caring for a child with biallelic RPE65-mediated IRD was taken from Al-Janabi et al. and applied to the mean number of carers per child as reported by the Office for National Statistics [36, 37]. In the absence of other data, it is assumed that the disutility for carers of adults with biallelic RPE65-mediated IRD is half that of carers of children with biallelic RPE65-mediated IRD.

\section{Resource Use and Cost Data}

Initial costs associated with $\mathrm{VN}$ were those for acquisition (list price), administration, monitoring, eligibility testing and adverse events (see supplementary materials for further details).

Ongoing healthcare costs associated with disease management were assumed to vary by age group and health state (see supplementary materials for further details); scenarios were considered in which broader societal costs were included.

All costs were valued in 2019 UK pounds; where necessary, costs were inflated using healthcare-specific inflation indices [38].

\section{Sensitivity Analysis}

Parameter uncertainty was explored using univariate sensitivity analysis and probabilistic

Table 4 Health state utility values

\begin{tabular}{lllllr}
\hline HRQoL instrument & \multicolumn{4}{l}{ Utility value, mean $($ SD $)$} \\
\cline { 2 - 6 } & HS1 & HS2 & HS3 & HS4 & \multicolumn{1}{c}{ HS5 } \\
\hline EQ-5D-5L & $0.71(0.09)$ & $0.62(0.04)$ & $0.52(0.07)$ & $0.35(0.06)$ & $0.15(0.11)$ \\
HUI3 & $0.52(0.16)$ & $0.36(0.11)$ & $0.22(0.10)$ & $0.14(0.09)$ & $-0.04(0.07)$ \\
\hline
\end{tabular}

Key: HS1, moderate visual impairment; HS2, severe visual impairment; HS3, profound visual impairment; HS4, counting fingers; HS5, hand motion, light perception to no light perception

$H R Q O L$ health-related quality of life, $S D$ standard deviation 
sensitivity analysis (PSA). In univariate sensitivity analysis, all model parameters were systematically and independently varied over a plausible range determined by either the 95\% confidence interval or $\pm 15 \%$ where no estimates of precision were available. The ICER was recorded at the upper and lower values to produce a tornado diagram. In PSA, all model parameters were assigned distributions and varied jointly; 10,000 Monte Carlo simulations were recorded, and the cost-effectiveness plane (CEP) and cost-effectiveness acceptability curve (CEAC) were generated.

Structural uncertainty was testing using scenario analyses, in which key assumptions were varied and ICERs were reported (Table 5).

Table 5 Scenario analyses

\begin{tabular}{|c|c|c|}
\hline Area of uncertainty & Base case & Scenarios \\
\hline Perspective & $\begin{array}{l}\text { Healthcare } \\
\text { system }\end{array}$ & $\begin{array}{l}\text { UK } \\
\text { government } \\
\text { Societal }\end{array}$ \\
\hline Discount rate & $\begin{array}{l}3.5 \% \text { for costs } \\
\text { and } \\
\text { outcomes }\end{array}$ & $\begin{array}{l}1.5 \% \text { for costs } \\
\text { and } \\
\text { outcomes }\end{array}$ \\
\hline Health state definition & Average eye & Best-seeing eye \\
\hline $\begin{array}{l}\text { Source of baseline } \\
\text { characteristics }\end{array}$ & Phase III trial & $\begin{array}{l}\text { Natural } \\
\text { history data }\end{array}$ \\
\hline $\begin{array}{l}\text { Transition probability } \\
\text { matrices in initial } \\
\text { phase }\end{array}$ & $\begin{array}{l}\text { Crossover data } \\
\text { excluded }\end{array}$ & $\begin{array}{l}\text { Crossover data } \\
\text { included }\end{array}$ \\
\hline $\begin{array}{l}\text { Duration of treatment } \\
\text { effect }\end{array}$ & 40 years & $\begin{array}{l}20 \text { years } \\
30 \text { years } \\
\text { Lifetime }\end{array}$ \\
\hline $\begin{array}{l}\text { Multistate survival } \\
\text { model distribution }\end{array}$ & Weibull & $\begin{array}{l}\text { Exponential } \\
\text { Gompertz } \\
\text { Log-logistic } \\
\text { Log-normal }\end{array}$ \\
\hline Utility values & EQ-5D-5L & HUI3 \\
\hline
\end{tabular}

\section{RESULTS}

\section{Base Case Results}

$\mathrm{VN}$ is associated with incremental costs of $£ 612,404$ and incremental QALYs of 6.4, resulting in an ICER of $£ 95,072$ per QALY gained (Table 6). Although the acquisition cost of $\mathrm{VN}$ leads to a net incremental cost in the VN arm, modest cost offsets are achieved by reduced expenditure on healthcare resource use.

The cost-effectiveness threshold for the NICE HST programme is a most plausible ICER of $£ 100,000$ per QALY gained. If $>10$ additional QALYs are gained, a QALY weighting between 1 and 3 may be applied, using equal increments. Voretigene neparvovec is associated with 20.5 additional undiscounted QALYs compared with BSC; the additional QALY weighting applied to treatments offering $>10$ additional QALYs means that an ICER of up to $£ 205,000$ per QALY gained could be considered cost-effective under this framework.

Table 6 Base case results

\begin{tabular}{|c|c|c|c|}
\hline & BSC & $\mathbf{V N}$ & Incremental \\
\hline $\begin{array}{l}\text { VN acquisition }{ }^{\mathrm{a}} \text {, } \\
\text { administration and } \\
\text { monitoring costs }\end{array}$ & $£ 0$ & $£ 617,873$ & $£ 617,873$ \\
\hline $\begin{array}{l}\text { Eligibility testing } \\
\text { costs }\end{array}$ & $£ 0$ & $£ 142$ & $£ 142$ \\
\hline Adverse event costs & $£ 0$ & $£ 165$ & $£ 165$ \\
\hline $\begin{array}{l}\text { Healthcare resource } \\
\text { use costs }\end{array}$ & $£ 57,050$ & $£ 51,274$ & $-£ 5776$ \\
\hline Total costs & $£ 57,050$ & $£ 669,454$ & $£ 612,404$ \\
\hline Total QALYs & 9.8 & 16.3 & 6.4 \\
\hline ICER & - & - & $£ 95,072$ \\
\hline
\end{tabular}

$B S C$ best supportive care, $C F$ counting fingers, $H M$ hand motion, ICER incremental cost-effectiveness ratio, $Q A L Y$ quality-adjusted life-year, $V I$ visual impairment, $V N$ voretigene neparvovec

${ }^{a}$ List price-note that in the UK a confidential discount to the list price is available 


\section{Univariate Sensitivity Analysis}

Results for the ten most influential parameters identified by univariate sensitivity analysis are presented in Fig. 2. Six of the ten most influential parameters are those describing the longterm multistate survival model (i.e., the ancillary and constant terms for the Weibull model and the coefficients for four of the ten health state transitions); however, this result should be treated with caution given that highly correlated parameters (i.e., the regression coefficients) are being varied as if they are independent from one another. Other influential parameters include the health state utility values.

\section{Probabilistic Sensitivity Analysis}

The results of 10,000 PSA simulations were plotted on the CEP (Fig. 3) and a CEAC was generated (Fig. 4). The average incremental costs over the simulated results were $£ 611,203$ and the average incremental QALYs were 6.4, giving a probabilistic ICER of $£ 95,813$; this is highly congruent with deterministic changes in costs and QALYs of $£ 612,404$ and 6.4, respectively. The proportion of simulations considered cost-effective when accounting for the additional QALY weighting for treatments with significant QALY gains (i.e., > 10) was 71\%.

\section{Scenario Analysis}

Scenario analyses are presented in Fig. 5. Scenarios associated with increases to the ICER of $>$ $10 \%$ include assuming a duration of treatment effect of 20 or 30 years and assuming the lognormal or exponential distribution for the multistate survival model. Scenarios in which a societal perspective is considered, discount rates of $1.5 \%$ are applied, or a lifetime treatment effect is assumed were associated with substantial decreases in the ICER.

\section{DISCUSSION}

At list price, $\mathrm{VN}$ is associated with an ICER of $£ 95,072$ per QALY gained versus BSC. The model predicts a significant QALY gain of 20.5 QALYs (undiscounted), so an ICER of up to $£ 205,000$ per QALY gained could be considered cost-effective under the NICE HST framework because of additional QALY weighting; VN is therefore considered cost-effective at list price.

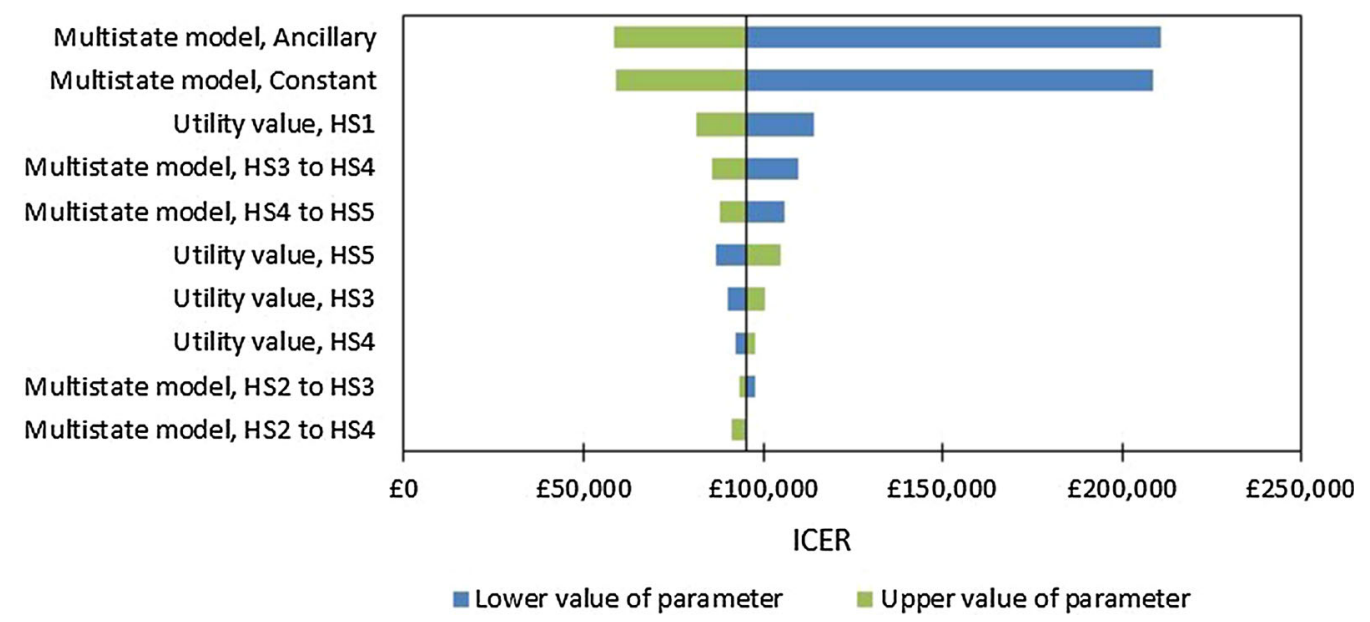

Fig. 2 Results of univariate sensitivity analysis (tornado diagram). Key: HS1, moderate visual impairment; HS2, severe visual impairment; HS3, profound visual impairment; HS4, counting fingers; HS5, hand motion, light perception to no light perception. In a tornado diagram, the $Y$-axis is centred on the base case ICER; for each parameter, the ICERs at the upper and lower values of the parameter are recorded and presented in green and blue, respectively, for the ten most influential parameters. ICER incremental cost-effectiveness ratio 


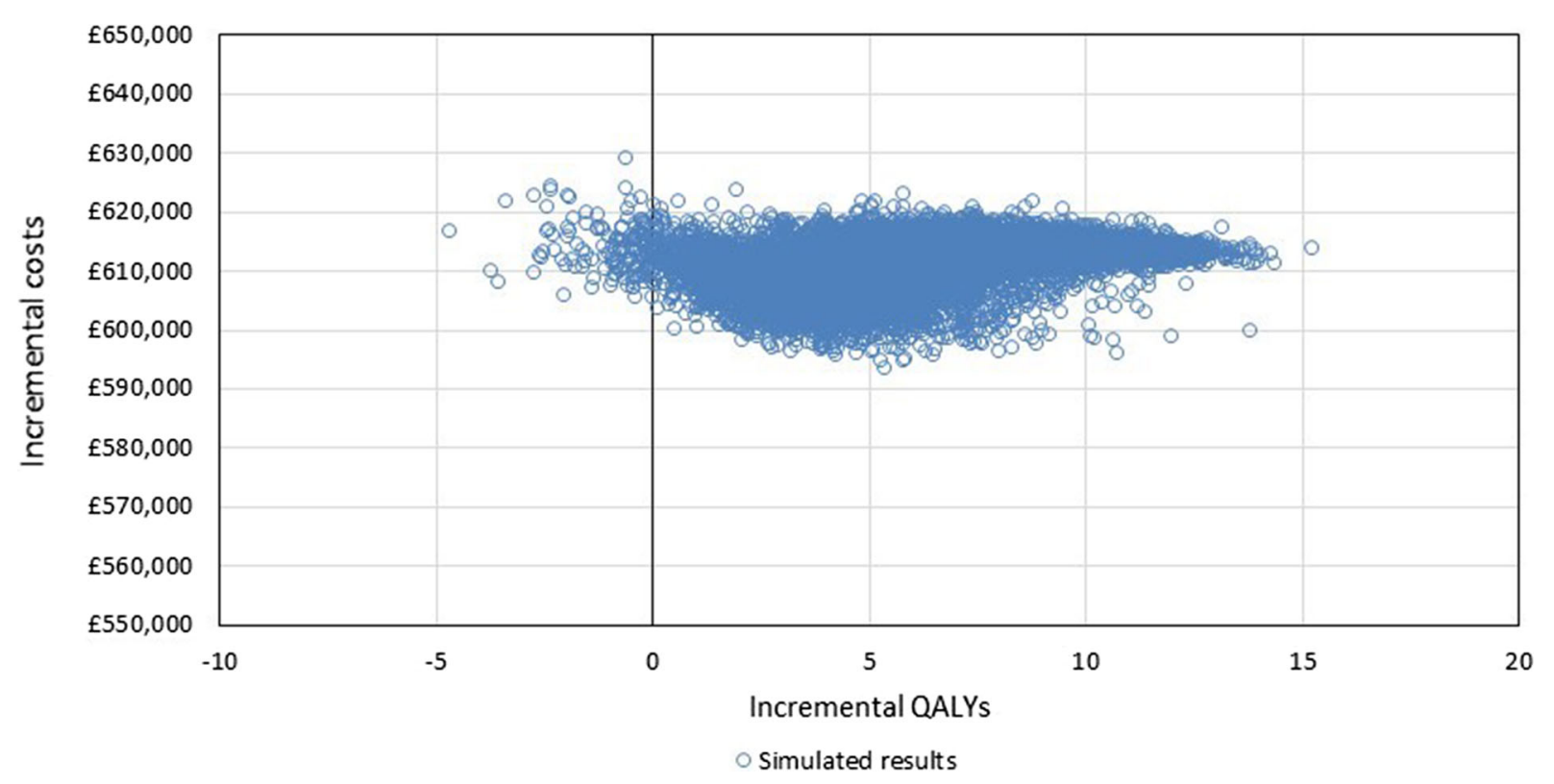

Fig. 3 Cost-effectiveness plane. $Q A L Y$ quality-adjusted life-year

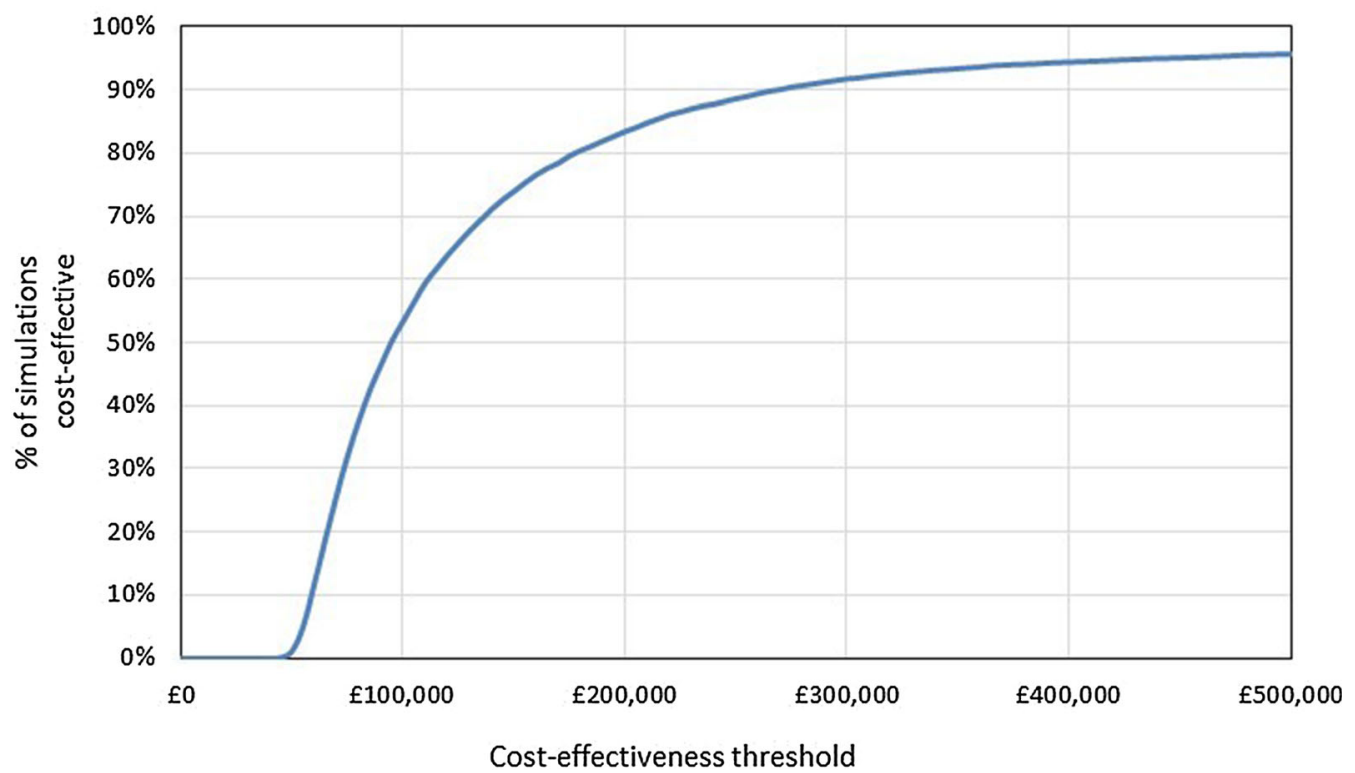

Fig. 4 Cost-effectiveness acceptability curve. A PSA simulation is considered to be cost-effective at a specific costeffectiveness threshold if the ICER for the simulation falls below that threshold. For example, in $52 \%$ of simulations,

A confidential discount to the list price (i.e., a patient access scheme) for VN has been agreed with the Department of Health, so in practice the true ICER will be lower.
VN was associated with an ICER of $<£ 100,000$ per QALY. ICER incremental cost-effectiveness ratio, PSA probabilistic sensitivity analysis, $Q A L Y$ quality-adjusted life year, $V N$ voretigene neparvovec

The results of the analysis were most sensitive to parameters defining the long-term multistate survival model, the health state utility values and the duration of treatment effect. 


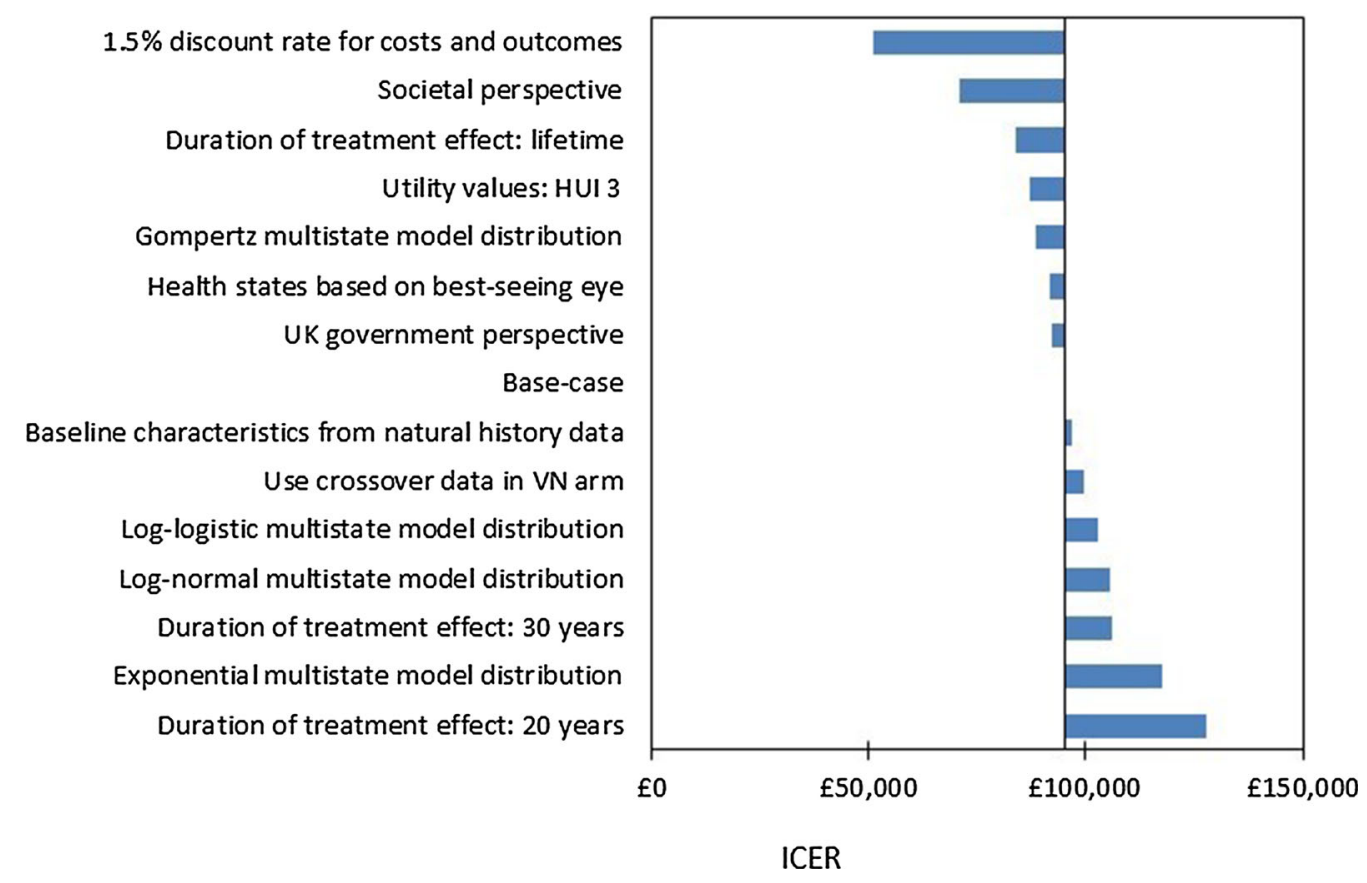

Fig. 5 Results of scenario analyses. ICER incremental cost-effectiveness ratio, $V N$ voretigene neparvovec

Seventy-one per cent of simulations would be considered cost-effective assuming the effective NICE HST weighted threshold given the additional QALY weighting.

A key strength of the analysis was the use of a bespoke study in which utility values in patients with biallelic RPE65-mediated IRD were estimated. The study made use of input from six retinal experts with experience in IRD, and vignettes were developed with input from an expert advisory board, patients and carers, and interviews with clinicians [29]; in the context of an ultra-orphan condition, this level of input from patients, carers and healthcare professionals is substantial. Previous analyses have relied on health-related quality of life data from older populations with different vision conditions [39].

Although improvements in VA and VF associated with VN were captured in the model, it was not possible to capture improvements in either MLMT (the primary trial endpoint) or light sensitivity, as no long-term data are available for these endpoints. Given that $\mathrm{VN}$ is associated with benefits beyond those captured by $\mathrm{VA}$ and $\mathrm{VF}$, the modelled benefit of $\mathrm{VN}$ is expected to be underestimated, resulting in a conservative estimate of cost-effectiveness.

A range of scenarios were considered, and the results were found to be relatively robust to alternative assumptions. All scenario analysis results are in the range of $£ 51,241-£ 127,800$ per QALY.

An inevitable limitation of rare disease trials is small sample sizes. The study upon which this model was built included 31 patients, of which 29 were treated. In the model, health state transitions in both the initial and long-term phase were based on low patient numbers ( $n=29$ and $n=68$, respectively), increasing the level of uncertainty in model outcomes.

In the absence of long-term data, there was also uncertainty around the long-term treatment effect associated with VN. To date, there is no evidence of loss of treatment effect over time-improvements in light sensitivity (measured by FST, which is correlated with MLMT [40]) in Study 101/102 and improvements in MLMT and FST in Study 301 were maintained through to the latest published time points $[19,20]$.

Furthermore, it is anticipated that the RPE65 gene will remain active during the lifetime of 
retinal pigment epithelium cells, which, in a normal state, do not undergo mitosis on a regular basis like gastrointestinal or skin epithelial cells; they form early in development and subsequently remain dormant, undergoing minimal proliferation throughout life. Additionally, vector delivery, surgical techniques and dosing in the $\mathrm{VN}$ trials were optimised based on lessons learned from other gene therapy trials, and VN was developed with an improved understanding of vector design and manufacturing [41].

Cost-effectiveness analyses have also been performed by the Institute for Clinical and Economic Review (Zimmermann et al. [39]) and by Johnson et al. [42], both conducted from a US perspective. The key differences among the three analyses are the duration of treatment effect, the health state utility values and the approach to modelling long-term changes in VA and VF. The analysis conducted by Zimmermann assumed a 10-year treatment effect with a 10-year waning period, utility values derived from patients with diabetic retinopathy and changes in VA and VF over time based on simple functions fit to digitised natural history data. Compared with the Zimmermann analysis, our analysis and the one by Johnson et al. benefit from access to patient-level data and a bespoke utility study specific to patients with IRD. Additionally, our assumptions may be considered to be relatively conservative compared with the study by Johnson et al., particularly regarding the duration of treatment effect (40 years in our analysis versus lifetime in Johnson et al.) and the exclusion of societal costs in our base case. Scenarios presented by Johnson et al. in which societal costs are excluded and the treatment effect of $\mathrm{VN}$ is reduced by either $10 \%$ or $50 \%$ after 3 years are relatively congruent with our analysis $(\$ 87,209$ and $\$ 136,452$ per QALY, respectively, compared with $£ 95,072$ per QALY).

The estimates presented in this analysis are consistent with a 2019 study, in which the lifetime QALY gain associated with gene therapy in individuals with retinal dystrophies was found to be 14.3 (compared with 20.5 QALYs in our study) [41].

\section{CONCLUSIONS}

Voretigene neparvovec is a cost-effective use of NHS resources in the UK at list price, and in practice cost-effectiveness is further improved with the application of the confidential discount agreed with the Department of Health. This study demonstrates the possibility for innovative and novel gene therapies to be costeffective despite high upfront costs because of the potential for substantial lifelong benefits.

\section{ACKNOWLEDGEMENTS}

Funding. Sponsorship for this study, the Rapid Service and Open Access Fees were funded by Novartis Pharma AG. All authors had full access to all the data in this study and take complete responsibility for the integrity of the data and accuracy of the data analysis.

Medical Writing Assistance. Medical writing assistance in the preparation of this article was provided by Dr Chris Hellmund of Source Health Economics. Support for this assistance was funded by Novartis Pharma AG.

Authorship. All named authors meet the International Committee of Medical Journal Editors (ICMJE) criteria for authorship for this article, take responsibility for the integrity of the work as a whole, and have given their approval for this version to be published.

Disclosures. Elizabeth Hancock, Hannah Lomax and David Trueman are employees of Source Health Economics, which received funding from Novartis Pharma AG to conduct the study. Daniel Viriato is an employee of Novartis Pharma AG, which funded the study. Raisa Sidhu and Natalie Bennett are employees of Novartis Pharmaceuticals UK Limited. Robert MacLaren has previously advised NICE, Spark Therapeutics, Biogen and Novartis through independent consultancy agreements. No fee or consultancy agreement was involved in preparing this article. Robert MacLaren receives grant funding from the Oxford NIHR 
Biomedical Research Centre, part of which relates to health economics of retinal gene therapy.

Compliance with Ethics Guidelines. This article is based on previously conducted studies and does not contain any studies with human participants or animals performed by any of the authors. The economic model uses data from a previously published phase III trial [2].

Data Availability. All shareable data generated or analysed during this study are included in this published article/as supplementary information files.

Open Access. This article is licensed under a Creative Commons Attribution-NonCommercial 4.0 International License, which permits any non-commercial use, sharing, adaptation, distribution and reproduction in any medium or format, as long as you give appropriate credit to the original author(s) and the source, provide a link to the Creative Commons licence, and indicate if changes were made. The images or other third party material in this article are included in the article's Creative Commons licence, unless indicated otherwise in a credit line to the material. If material is not included in the article's Creative Commons licence and your intended use is not permitted by statutory regulation or exceeds the permitted use, you will need to obtain permission directly from the copyright holder. To view a copy of this licence, visit http://creativecommons.org/licenses/bync/4.0/.

\section{REFERENCES}

1. RetNet: summaries of genes and loci causing retinal diseases. https://sph.uth.edu/retnet/sum-dis.htm. Accessed 16 Jan 2020.

2. Russell S, Bennett J, Wellman JA, Chung DC, Yu Z-F, Tillman A, Wittes J, Pappas J, Elci O, McCague S, Cross D, Marshall KA, Walshire J, Kehoe TL, Reichert H, Davis M, Raffini L, George LA, Hudson FP, Dingfield L, Zhu X, Haller JA, Sohn EH, Mahajan VB, Pfeifer W, Weckmann M, Johnson C, Gewaily D, Drack A, Stone E, Wachtel K, Simonelli F, Leroy
BP, Wright JF, High KA, Maguire AM. Efficacy and safety of voretigene neparvovec (AAV2-hRPE65v2) in patients with RPE65-mediated inherited retinal dystrophy: a randomised, controlled, open-label, phase 3 trial. Lancet. 2017;390:849-60. https://doi. org/10.1016/S0140-6736(17)31868-8.

3. National Institute for Health and Care Excellence (2019) Voretigene neparvovec for treating inherited retinal dystrophies caused by RPE65 gene mutations. https://www.nice.org.uk/guidance/hst11. Accessed 16 Jan 2020.

4. National Library of Medicine (US) Retinitis pigmentosa. https://ghr.nlm.nih.gov/condition/ retinitis-pigmentosa. Accessed 16 Jan 2020.

5. RNIB (2017) Retinitis pigmentosa and other inherited retinal dystrophies. https://www.rnib.org.uk/ sites/default/files/Understanding_Retinitis_Pigmen tosa.pdf. Accessed 16 Jan 2020.

6. Pennesi M, Weleber R, Yang P Retinitis pigmentosa. https://bestpractice.bmj.com/topics/en-gb/1144. Accessed 16 Jan 2020.

7. RNIB (2016) Children and young people in England: RNIB evidence-based review. https://www. rnib.org.uk/sites/default/files/Evidence\%20Based\% 20Review\%20CYP\%20-\%20England-A.pdf. Accessed 16 Jan 2020.

8. Bhuvaneswari M, Immanuel Selvaraj C, Selvaraj B, Srinivasan T. Assessment of psychological and psycho-physiological problems among visually impaired adolescents. Iran J Psychiatry Behav Sci. 2016;10:e3895. https://doi.org/10.17795/ijpbs3895.

9. Bolat N, Doğangün B, Yavuz M, Demir T, Kayaalp L. Depression and anxiety levels and self-concept characteristics of adolescents with congenital complete visual impairment. Turk Psikiyatri Dergisi Turk J Psychiatry. 2011;22:77-82.

10. Ishtiaq R, Chaudhary $\mathrm{MH}$, Rana MA, Jamil AR. Psychosocial implications of blindness and low vision in students of a school for children with blindness. Pak J Med Sci. 2016;32:431-4. https:// doi.org/10.12669/pjms.322.8737.

11. Mojon-Azzi SM, Sousa-Poza A, Mojon DS. Impact of low vision on well-being in 10 European countries. Ophthalmol J Int D'ophtalmol Int J Ophthalmol Zeitschrift Fur Augenheilkunde. 2008;222:205-12. https://doi.org/10.1159/000126085.

12. Chaumet-Riffaud AE, Chaumet-Riffaud P, Cariou A, Devisme C, Audo I, Sahel J-A, Mohand-Said S. Impact of retinitis pigmentosa on quality of life, mental health, and employment among young 
adults. Am J Ophthalmol. 2017;177:169-74. https://doi.org/10.1016/j.ajo.2017.02.016.

13. Leger D, Guilleminault C, Defrance R, Domont A, Paillard M. Prevalence of sleep/wake disorders in persons with blindness. Clin Sci. 1999;97:193-9 (London, England: 1979).

14. Braich PS, Jackson M, Knohl SJ, Bhoiwala D, Gandham SB, Almeida D. Burden and depression in caregivers of blind patients in New York State. Ophthalmic Epidemiol. 2016;23:162-70. https:// doi.org/10.3109/09286586.2015.1099684.

15. Braich PS, Lal V, Hollands S, Almeida DR. Burden and depression in the caregivers of blind patients in India. Ophthalmology. 2012;119:221-6. https:// doi.org/10.1016/j.ophtha.2011.07.038.

16. Viriato D, Glen F, Bennett N, Aouadj C, Hancock E, Lomax H, Sidhu R. (PSS6) What is the lifetime cost of blindness in people with RPE65-mediated inherited retinal dystrophy in the UK? Value Health. 2019;22(Supplement 3):S886-7.

17. Food and Drug Administration Luxturna. https:// www.fda.gov/vaccines-blood-biologics/cellulargene-therapy-products/luxturna. Accessed 16 Jan 2020 .

18. European Medicines Agency Luxturna. https:// www.ema.europa.eu/en/medicines/human/EPAR/ luxturna. Accessed 16 Jan 2020.

19. Drack AV, Bennett J, Russell S, High KA, Yu Z-F, Tillman A, Chung DC, Reape KZ, Ciulla T, Maguire AM. How long does gene therapy last? 4 Year follow-up of Phase 3 Voretigene Neparvovec Trial in RPE65-associated LCA/inherited retinal disease. J AAPOS. 2019;23(4):e7.

20. Chung DC, Lee K, Reape KZ, High K, Lacey S, Viriato D. Long-term effect of voretigene neparvovec on the full-field light sensitivity threshold test of patients with RPE65 mutation-associated inherited retinal dystrophy-post hoc analysis of Phase I trial data. Investig Ophthalmol Vis Sci. 2019;60:3398.

21. Maguire AM, Russell S, Wellman JA, Chung DC, Yu Z-F, Tillman A, Wittes J, Pappas J, Elci O, Marshall KA, McCague S, Reichert H, Davis M, Simonelli F, Leroy BP, Wright JF, High KA, Bennett J. Efficacy, safety, and durability of voretigene neparvovec-rzyl in RPE65 mutation-associated inherited retinal dystrophy. Ophthalmology. 2019;126(9):1273-85. https://doi.org/10.1016/j.ophtha.2019.06.017.

22. York Health Economics Consortium (2016) Quality-adjusted life year (QALY). https://yhec.co.uk/ glossary/quality-adjusted-life-year-qaly/. Accessed 16 Jan 2020.
23. National Institute for Health and Care Excellence (2017) Interim process and methods of the highly specialised technologies programme updated to reflect 2017 changes. https://www.nice.org.uk/ Media/Default/About/what-we-do/NICE-guidance/ NICE-highly-specialised-technologies-guidance/ HST-interim-methods-process-guide-may-17.pdf. Accessed 16 Jan 2020.

24. National Institute for Health and Care Excellence Guide to the methods of technology appraisal 2013. https://www.nice.org.uk/process/pmg9/chapter/ foreword. Accessed 16 Jan 2020.

25. Chung DC, Bertelsen M, Lorenz B, Pennesi ME, Leroy BP, Hamel CP, Pierce E, Sallum J, Larsen M, Stieger K, Preising M, Weleber R, Yang P, Place E, Liu E, Schaefer G, DiStefano-Pappas J, Elci OU, McCague S, Wellman JA, High KA, Reape KZ. The natural history of inherited retinal dystrophy due to biallelic mutations in the RPE65 gene. Am J Ophthalmol. 2018. https://doi.org/10.1016/j.ajo.2018. 09.024 .

26. Crowther MJ, Lambert PC. Parametric multistate survival models: flexible modelling allowing transition-specific distributions with application to estimating clinically useful measures of effect differences. Stat Med. 2017;36(29):4719-42. https:// doi.org/10.1002/sim.7448.

27. Office for National Statistics Life tables, principal projection, England and Wales. https://www.ons. gov.uk/peoplepopulationandcommunity/birthsdea thsandmarriages/lifeexpectancies/datasets/lifetabl esprincipalprojectionenglandandwales. Accessed 13 Jan 2020.

28. Christ SL, Lee DJ, Lam BL, Zheng DD, Arheart KL. Assessment of the effect of visual impairment on mortality through multiple health pathways: structural equation modeling. Investig Ophthalmol Vis Sci. 2008;49(8):3318-23. https://doi.org/10. $1167 /$ iovs.08-1676.

29. Lloyd A, Piglowska N, Ciulla T, Pitluck S, Johnson S, Buessing M, O'Connell T. Estimation of impact of RPE65-mediated inherited retinal disease on quality of life and the potential benefits of gene therapy. $\mathrm{Br}$ J Ophthalmol. 2019;103(11):1610-4. https://doi. org/10.1136/bjophthalmol-2018-313089.

30. Pastores GB, Hughes J, Rogers Y, Stenson C, Clark A, Lloyd A, Alvarez I, Jain M, Kha A, Monavari A. 262-Estimation of resource use and quality of life in phenylketonuria (PKU) patients in Ireland. J Inborn Errors Metab Screen. 2017;5:118.

31. Lloyd ATI, Gallop K, Moseley S, Donato BMK, L'Italien G (2017) Effect of Asfotase Alfa treatment on health states and ambulatory function in patients with hypophosphatasia. J Bone Miner Res. 
32(Suppl 1). https://www.asbmr.org/education/ AbstractDetail?aid=01c2e170-e95c-4a2e-ab9e-2361 Ob76f658. Accessed 16 Jan 2020.

32. van Hout B, Janssen MF, Feng Y-S, Kohlmann T, Busschbach J, Golicki D, Lloyd A, Scalone L, Kind P, Pickard AS. Interim scoring for the EQ-5D-5L: mapping the EQ-5D-5L to EQ-5D-3L value sets. Value Health J Int Soc Pharmacoecon Outcomes Res. 2012;15(5):708-15. https://doi.org/10.1016/j. jval.2012.02.008.

33. Scottish Medicines Consortium (2020) Guidance to submitting companies for completion of New Product Assessment Form (NPAF). https://www. scottishmedicines.org.uk/media/5002/guidance-onnpaf.pdf. Accessed 16 Jan 2020.

34. National Institute for Health and Care Excellence (2018) Macular degeneration. Appendix J: Health economics. https://www.nice.org.uk/guidance/ ng82/evidence/appendix-j-health-economics-pdf170036251093. Accessed 13 Jan 2020.

35. Pershing S, Enns EA, Matesic B, Owens DK, Goldhaber-Fiebert JD. Cost-effectiveness of treatment of diabetic macular edema. Ann Intern Med. 2014;160(1):18-29. https://doi.org/10.7326/M130768 .

36. Al-Janabi H, Van Exel J, Brouwer W, Trotter C, Glennie L, Hannigan L, Coast J. measuring health spillovers for economic evaluation: a case study in meningitis. Health Econ. 2016;25(12):1529-44. https://doi.org/10.1002/hec.3259.

37. Office for National Statistics (2018) Families and Households: 2018. https://www.ons.gov.uk/people populationandcommunity/birthsdeathsandmarriag es/families/bulletins/familiesandhouseholds/2018. Accessed 13 Jan 2020.

38. Personal Social Services Research Unit Unit Costs of Health and Social Care 2019. https://www.pssru.ac. uk/project-pages/unit-costs/unit-costs-2019/. Accessed 16 Jan 2020.

39. Zimmermann M, Lubinga SJ, Banken R, Rind D, Cramer G, Synnott PG, Chapman RH, Khan S, Carlson J. Cost utility of voretigene neparvovec for biallelic RPE65-mediated inherited retinal disease. Value Health J Int Soc Pharmacoecon Outcomes Res. 2019;22(2):161-7. https://doi.org/10.1016/j. jval.2018.09.2841.

40. Chung DC, Russell SR, Bennett J, Maguire AM, Wellman JA, Yu ZF, Tillman A, High KA. Correlation of multi-luminance mobility testing with visual function tests in a phase 3 trial of voretigene neparvovec for biallelic RPE65-mediated inherited retinal disease. Investig Ophthalmol Vis Sci. 2017;58:3292.

41. Halioua-Haubold C-L, Jolly JK, Smith JA, PinedoVillanueva R, Brindley DA, MacLaren RE. Potential lifetime quality of life benefits of choroideremia gene therapy: projections from a clinically informed decision model. Eye. 2019;33(8):1215-23. https://doi.org/10.1038/s41433-019-0492-1.

42. Johnson S, Buessing M, O'Connell T, Pitluck S, Ciulla TA. Cost-effectiveness of voretigene neparvovec-rzyl vs standard care for RPE65-mediated inherited retinal disease. JAMA Ophthalmol. 2019. https://doi.org/10.1001/jamaophthalmol.2019.2512. 